\title{
An Evaluation of Light Distribution in the Exhibition Areas of the Mimesis Art Museum Designed by Alvaro Siza
}

\author{
Chang Sung Kim \\ Department of Architectural Engineering, Hyupsung University, Hwaseong Si, South Korea \\ Email: cskim815@daum.net
}

Received 4 October 2014; revised 15 November 2014; accepted 1 December 2014

Copyright (C) 2014 by author and Scientific Research Publishing Inc.

This work is licensed under the Creative Commons Attribution International License (CC BY). http://creativecommons.org/licenses/by/4.0/

c) (i) Open Access

\section{Abstract}

The works of Alvaro Siza have been referred that they were not the theoretical architecture but the sensual and experiential one. His works were designed on the base of their locality that each of them located. For the study, I selected a work of him, which was the Mimesis Art Museum at Paju in South Korea, and reviewed existing literatures to understand how he controlled the light and created the architectural spaces and forms in relation with the light, and I measured the illumination levels of the inside areas of the Mimesis Art Museum, and then, I surveyed the visitors' responses on the lighting conditions of the Mimesis Art Museum. The results of the measurements showed that the illumination levels of the Mimesis Art museum on the first floor were effectively controlled to display the art works. The illumination levels on the third floor, however, were much higher than recommended illumination values for museum because of less controlled natural light. Therefore, more considerations to control the natural light are needed to secure stable environment in the exhibition spaces. Meanwhile, the answers of questionnaires concerning the quality of lighting conditions in the Mimesis Art Museum showed that the natural light was so effective to light the museum although the natural light illuminated some areas of the museum with high illumination levels.

\section{Keywords}

Alvaro Siza, The Memesis Art Museum, Natural Light

\section{Introduction}

The light incredibly influences not only the visual perception of people but also their mentality, and evokes

How to cite this paper: Kim, C.S. (2014) An Evaluation of Light Distribution in the Exhibition Areas of the Mimesis Art Museum Designed by Alvaro Siza. Journal of Building Construction and Planning Research, 2, 227-243. 
unique feelings towards the perceived objects. In addition, the variation and fluidity of the light help them notice and feel the changing time. Therefore, the light has been considered as an essential element for architectural design, and it contributes to the prodigious progress of the architecture. By means of the light, we recognize the architectural space and form, and illuminate the interior spaces of buildings. The light also affects the psychological aspect of people by giving a sentimental side to architecture. It casts darkness and brightness to spaces so as to reveal rhythmic changes in the physical shape of building. As such, the light controls the behavior of people.

The property of the light to illuminate the indoor space of building can be different in accordance with the environmental context of the region that building is located. Such locality of building is the key aspect in making design strategies on how to induce the light to indoor space of building, how to maintain the brightness, and how to make indoor space comfortable. So, the light enables occupants of building feel cozy and makes indoor space more refined.

The light guides the visitors' movements in a building and enables them to perceive spatial characteristics of the building in more sentimental manner. The light also creates a distinctive feeling to a place in the building. The influx of the light to a space attracts the attention of people and, at the same time, diverts their attentions in the building, which again facilitates the visitors' movements. The visitors' circulation that regulates the sequence of space is a key element for the design of museums. Here, a space makes relations with other spaces, and they are eventually woven one another. While the visitors move around, the light delivers various spatial expressions to them by the change of the light, and it helps them to experience the aesthetic and artistic values of the building. The light helps the visitors to experience the building in the sentimental and psychological manners by organizing spaces with the shadow.

The light changes continuously over time, and it gives a changing atmosphere to the space according to the change of time. Such fluidity gives life to the space as if it were a living object. Thus, the light gives different feelings to the same physical space as time changes, and such altered feelings affect the sentiment of people. The space itself is in three-dimensional system. However, the light enables people to experience it in four-dimensional system by embracing the dimension of time when it is joined with the light.

In those regards, I had studied the theoretical basis of Alvaro Siza who used the natural light as one of the most important elements in his design phase, and analyzed his works to understand how to integrate the natural light into his works. For these purposes, I had analyzed three works of him such as the Museum for Ibere Camargo Foundation, the Aveiro Library and the Mimesis Art Museum in the preceding research [1]. For a follow up study of it, I selected the Mimesis Art Museum at Paju in South Korea, and reviewed existing literatures to understand how he controlled the light and created the architectural spaces and forms with the light [2] [3], and then, I measured illumination levels in the exhibition areas of the Mimesis Art Museum and surveyed the visitors' responses concerning the lighting conditions of it.

\section{Relationship of Light and Space Appeared in the Works of Alvaro Siza}

It has been referred that "The architecture of Alvaro Siza produces lasting impressions on people who visits his works in many aspects. It helps people sensually to explore light, textures, movements, and spaces in the architecture. The buildings he designed are like vectors that are drawn across the earth. His architecture helps people increase the experience of a place" [4]. Siza was willing to use the natural light to be accord with climatic characteristics of regions. And, he drew the natural light into indoor spaces, and made it harmonize with artificial lights in order to create a splendid space and inspire a stimulating impression (Figure 1 and Figure 2).

The indoor spaces created by the influx of the light make people experience a rich sense of fluidity in buildings. Such continuity of spaces can easily be experienced as they explore the inside and outside spaces of buildings. The shapes of buildings observed from the outside give strong geometric feelings while, in the inside spaces, they are mingled with the light generating a subtle delicacy of geometry. This overturned feelings from the inside and outside spaces provide a unique impression of the spatial continuity to people, and gives psychological stimulation to them [5]. Overall, the changing light in the spaces gives life to the spaces, which makes the spaces felt more fluid (Figure 3 and Figure 4).

One of the characteristics appeared in the works of Alvaro Siza is the external courtyards and the internal patios. Such void spaces influence the visitors' movements in building as well as the direct or indirect connection between the spaces, and the relationships between land and surrounding areas. The courtyard of Setúbal University 


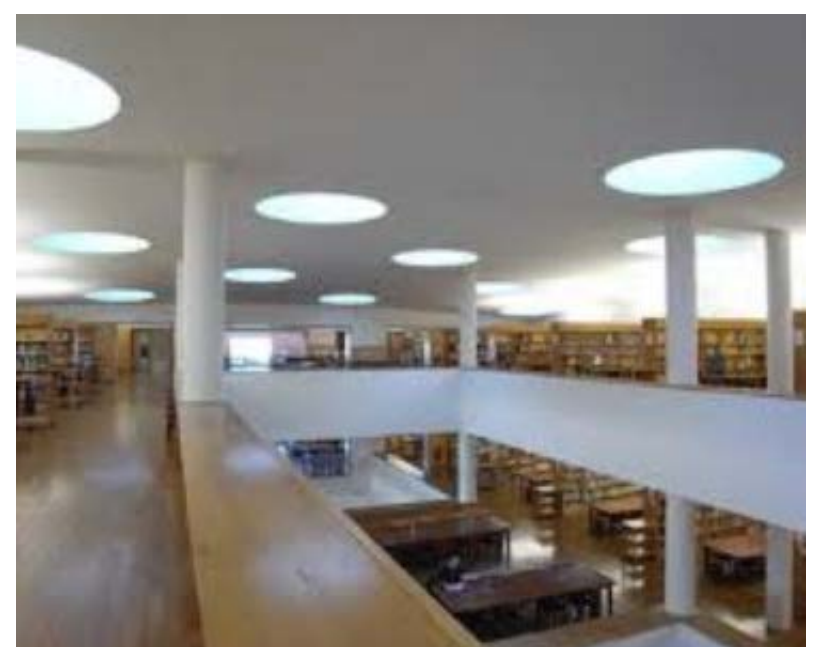

Figure 1. Aveiro Library.

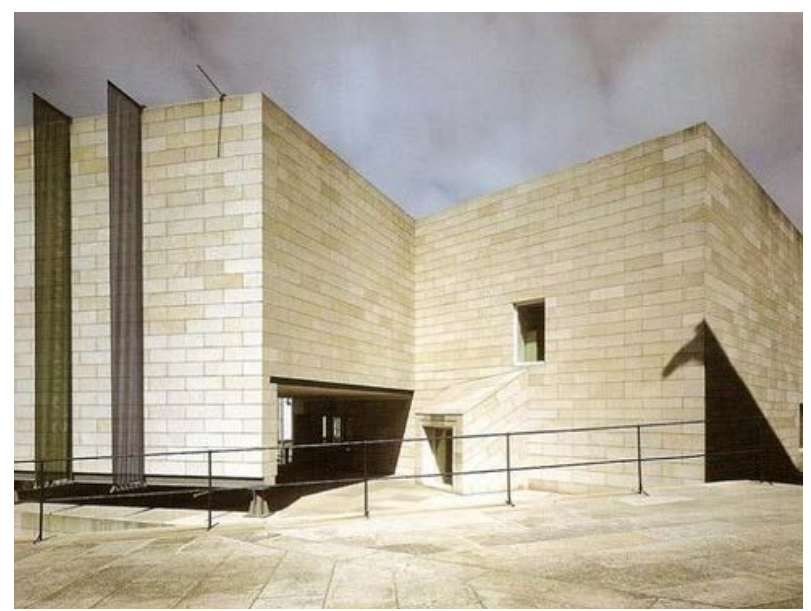

Figure 2. Galician Center for Contemporary Art.

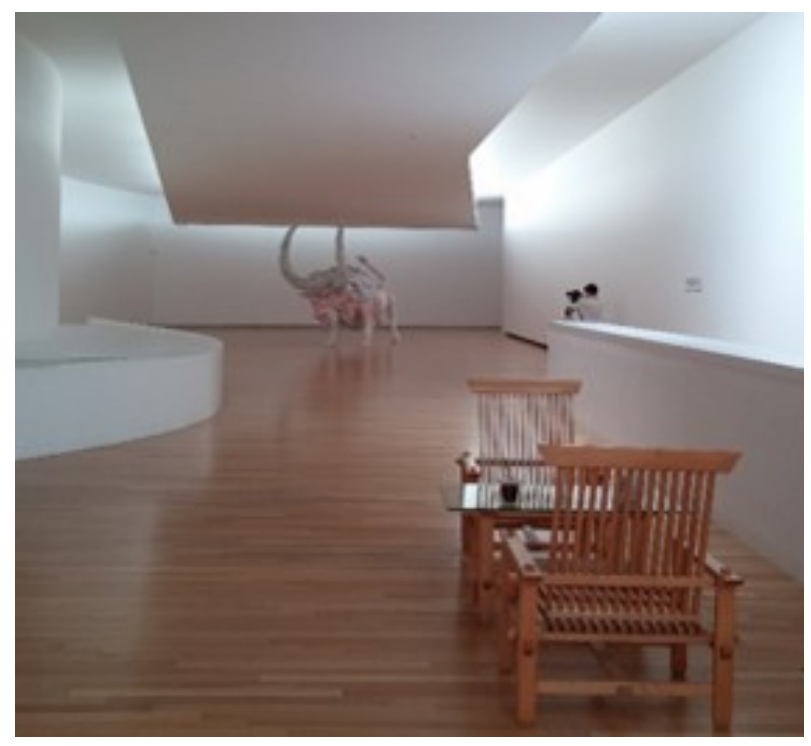

Figure 3. Mimesis Art Museum. 
influences the external circulation of the building and connects the spaces around the building (Figure 5). As the visitors walk along the geometric forms and floors of the building, they come across with an entrance of the building. At this point, the courtyard plays an important role for the visitors' movements. In addition, it works as the in-between space to connect the building and the surroundings. A void space alleviates the sense of pressure from the building mass and provides the visitors with a buffer zone between spaces. At the same time, it is where the light is captured to make the indoor spaces better-illuminated and felt cozy.

By embracing the building and its surrounding areas, a courtyard help establish an order of the visitors' movements, and, at the same time, creates a social space for them to communicate with one another. Here, their lives are accumulated, and the space becomes a place to help them experience the architecture itself in more dynamic ways. In this process, the refined light adds psychological impressions to people while the building maintains the urban context (Figure 6 and Figure 7).

\section{Analysis of Lighting Environment and Visitor's Satisfaction}

\subsection{Lighting Conditions of the Mimesis Art Museum}

The Mimesis Art Museum, which is located in Paju, South Korea, was designed in a free-flowing geometric

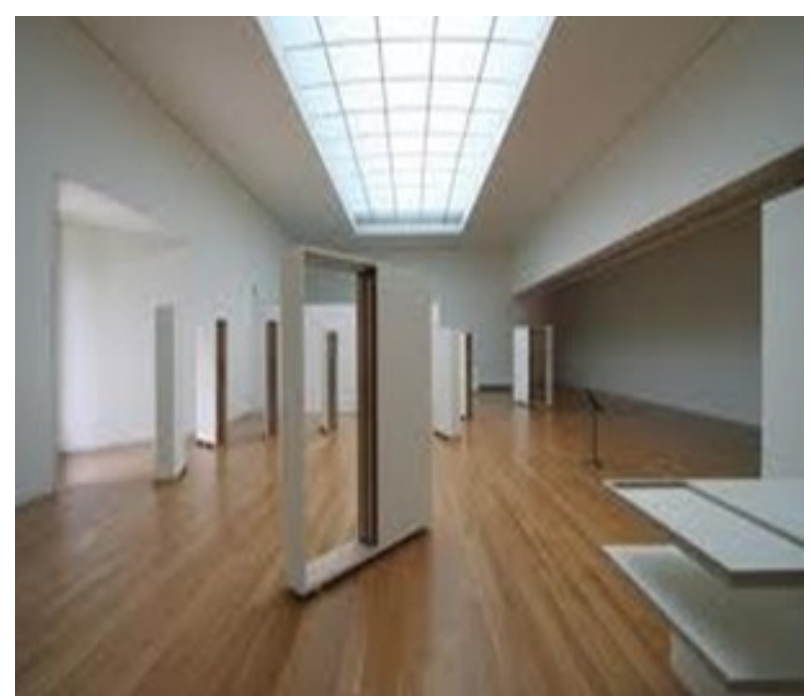

Figure 4. Museum for Ibere Camargo Foundation.

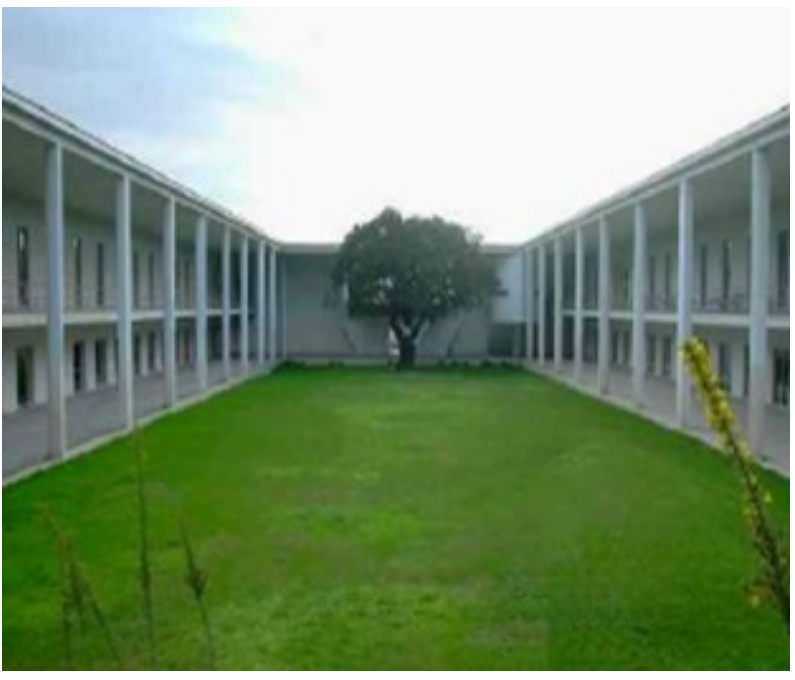

Figure 5. Court in Setúbal Teacher’s College. 


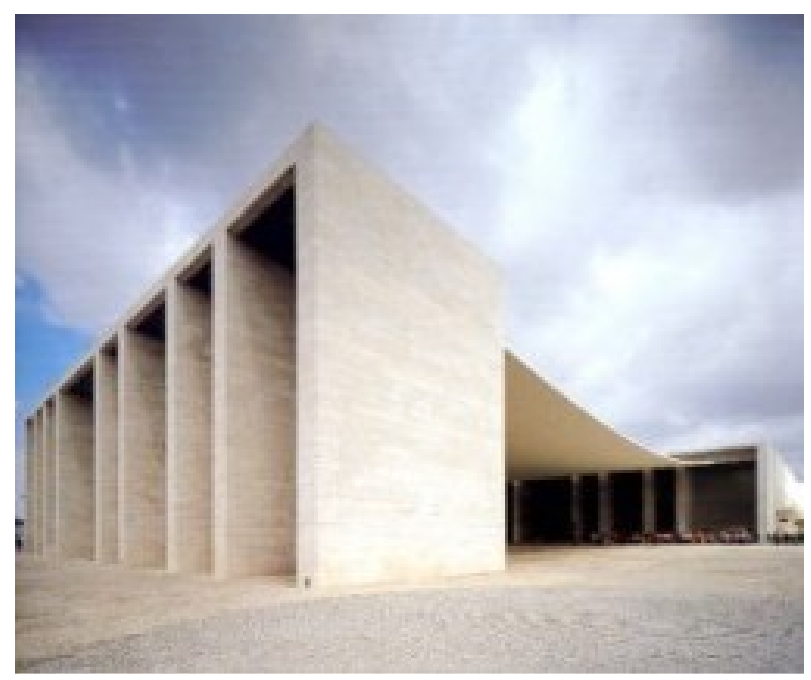

Figure 6. Portugal Pavilion.

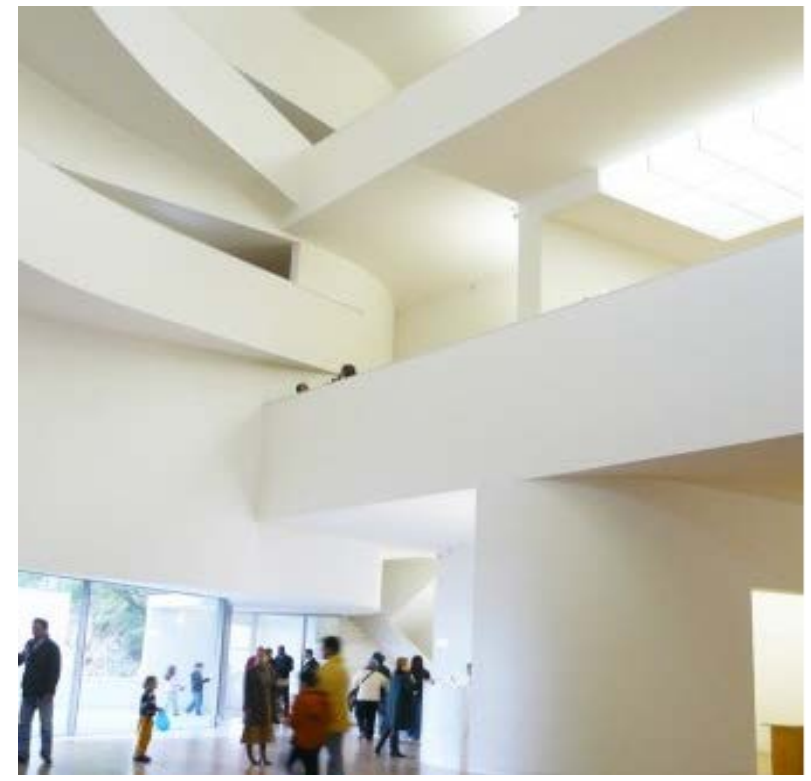

Figure 7. Museum for Ibere Camargo Foundation.

shape by Alvaro Siza. When he was designing it, he drew pictures of a cat curled up on the land. He applied these pictures to the museum design. The geometric form itself of the Mimesis Art Museum looks heavy as a solid mass. The pilotis on the first floor, however, supplement the shortcoming of the mass shape that might have been looked rather dull. In addition, they lead the visitors to the entrance offering sufficient opportunities to experience the exterior of the museum. Such architectural traits make the spaces look much roomier when the visitors enter the Mimesis Art Museum (Figures 8-10).

The void spaces in the inside and outside of the museum are the distinguishing features in the Mimesis Art Museum (Figures 11-13). The void space outside the building is surrounded by curves, giving an impression of variety and continuity in its form. It also helps bring the light deeper into the building. The inside void space opened from the first floor to the third floor is located in the lobby, which vertically connects the two spaces between the first and third floor. This design method allows the visitors to feel the sense of roominess in multiple directions. Alvaro Siza used the skylights as the principle light source to illuminate the inside areas, and they were supplemented by various windows and artificial lightings. This multiple illumination methods made exhibition environment of the museum much brighter and cozier. 


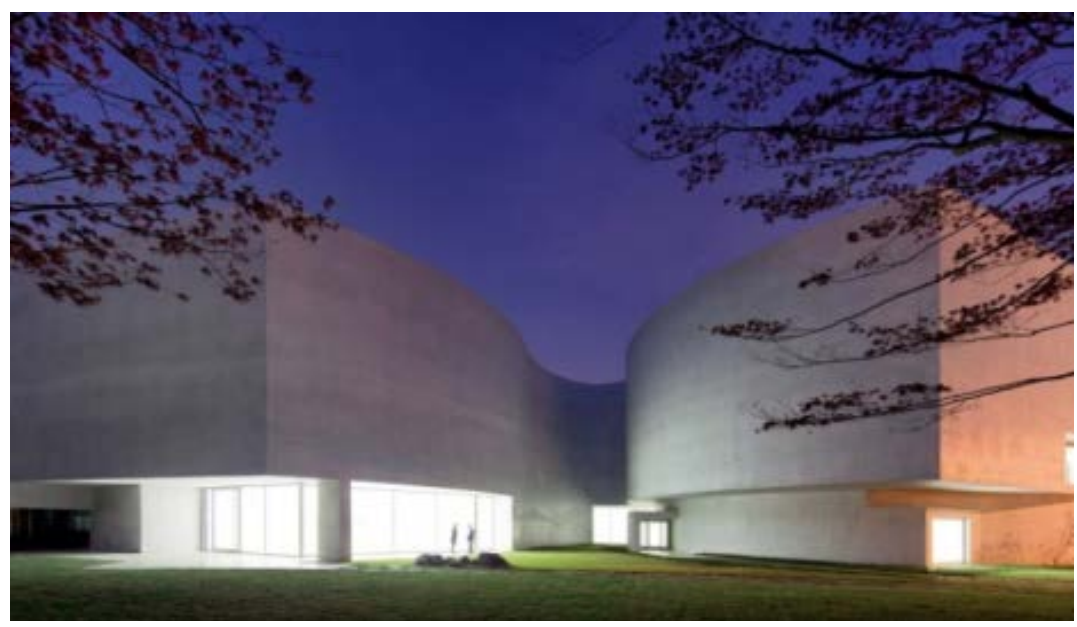

Figure 8. Front view.
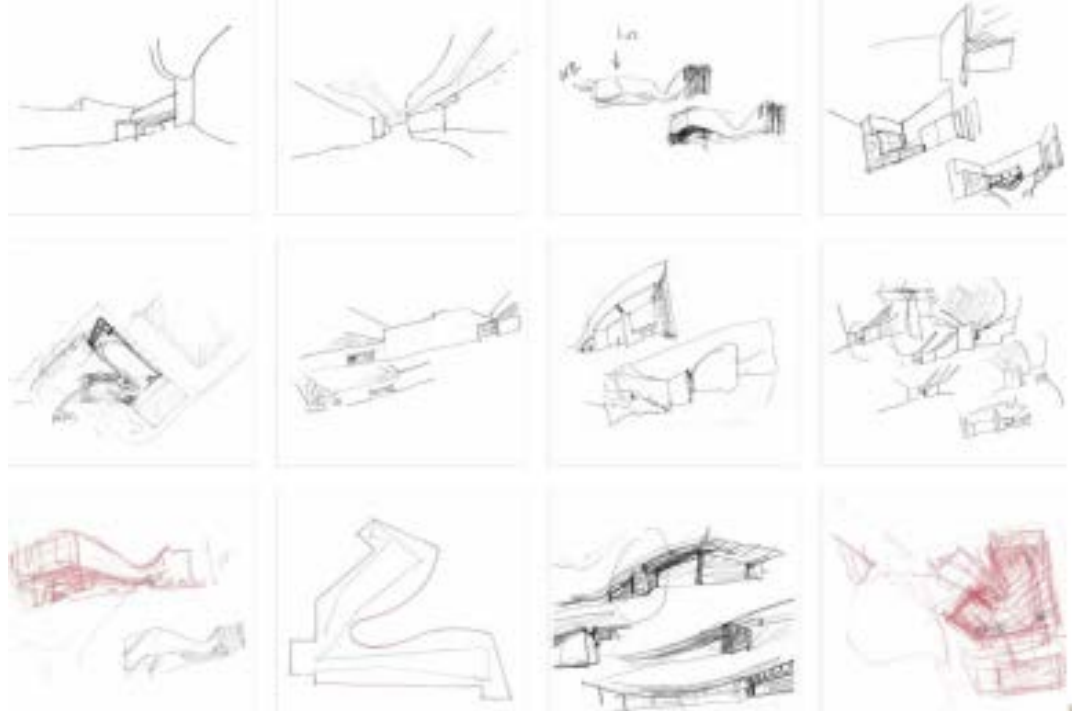

Figure 9. Sketch for Mimesis Art Museum.

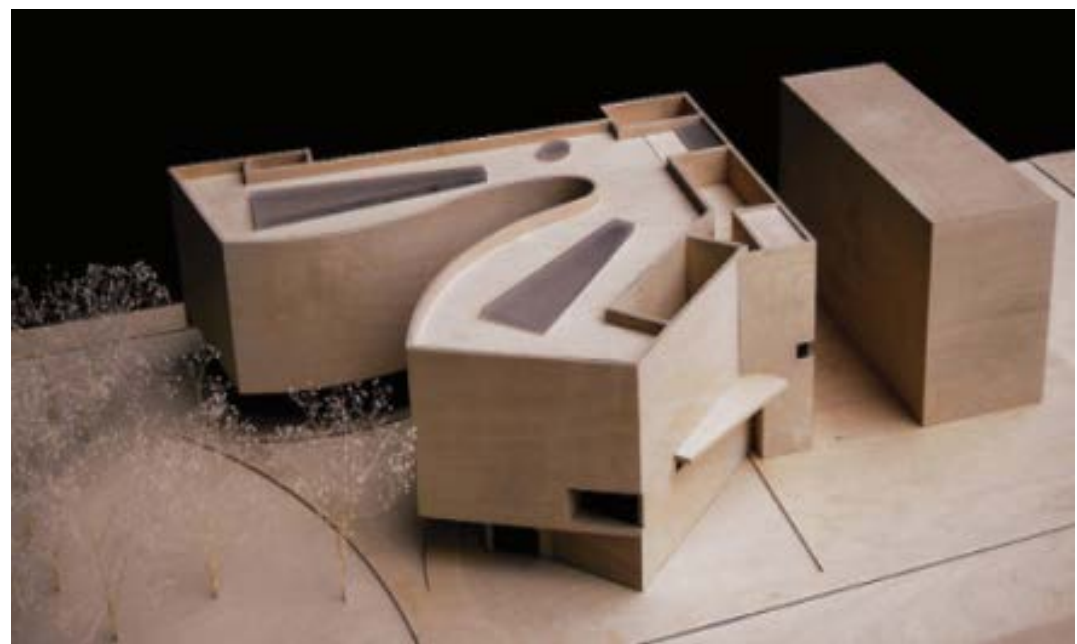

Figure 10. Scale model. 


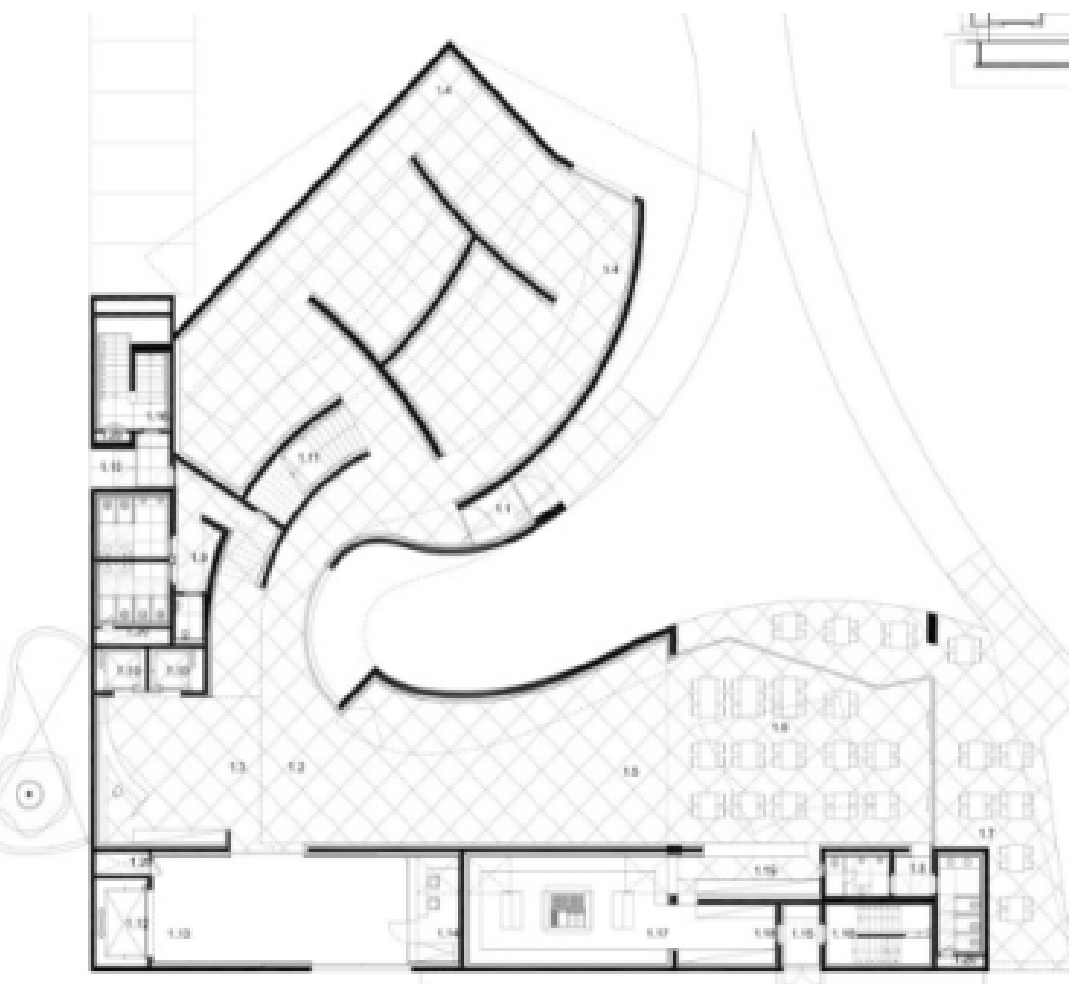

Figure 11. First floor plan.

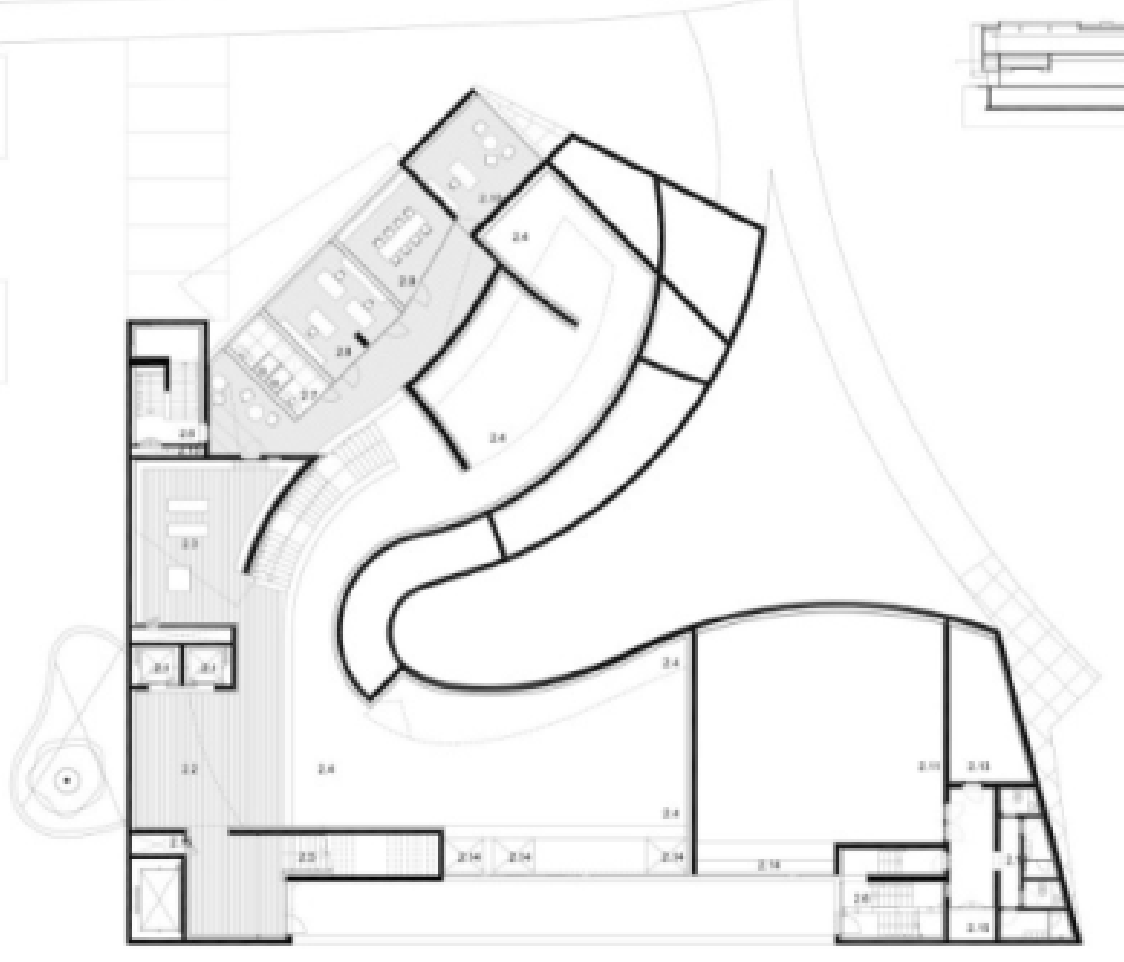

Figure 12. Second floor plan. 


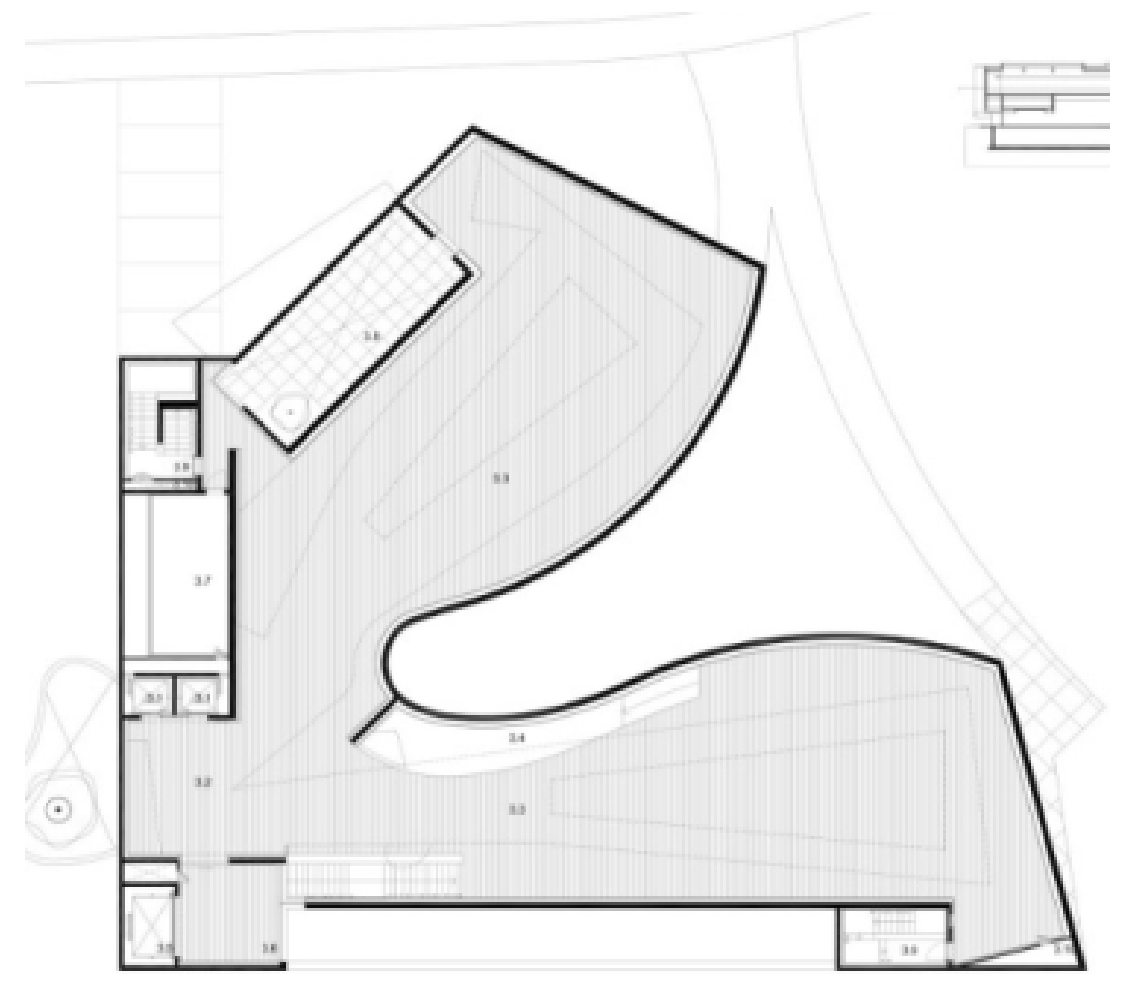

Figure 13. Third floor plan.

The Mimesis Art Museum displayed various exhibits such as sculpture, paintings and cartoons, etc. when I visited it to survey its lighting environment. The exhibition area on the first floor was illuminated with the natural light through a window as well as artificial lights on the ceiling (Figure 14). The exhibition area on the second floor was illuminated with the artificial light on the ceiling and the natural light through the skylight on the roof (Figure 15). The exhibition area on the third floor was illuminated with only natural light through the skylights and windows (Figure 16 and Figure 17). The natural light through skylights was scattered in several directions by the panels installed under the ceiling to protect exhibits from direct sunlight, and effectively illuminate the exhibition areas.

In general, the light consists of visible light and infrared and ultraviolet radiation. Among these three components, infrared radiation causes harmful drying shrinkage cracks to museum exhibits and ultraviolet radiation promotes discoloration [6] [7]. Therefore, careful control of the lighting is required to protect the exhibits from the light.

For the favorable environment of exhibition areas, it is necessary to maintain a certain level of illuminance level across the exhibition area. The IESNA [8] suggested the recommendation for the appropriate illuminance level in accordance with the nature of indoor space and duties. Especially for the exhibition space, the recommendation distinguishes three types of display contents by the degree to which photochemical damage is probable: highly susceptible, moderately susceptible, and least susceptible (Table 1).

A measurement was conducted with illuminance meter to evaluate the lighting conditions of the Mimesis Art Museum for 2 days on June 3rd and 8th, 2014. The measurement points to measure the horizontal illumination levels were set up 1 meter high on the floors, and they were measured at 78 and 153 measurement points, respectively, on the first and third floor. The measurements on the first floor were showed in Figure 18 and Table 2. According to the results, the illumination levels on the first floor were the maximum illumination level of 757 lux, minimum of 130 lux and average of 239 lux. The measurements on the third floor showed the maximum illumination level of 892 lux, minimum of 260 lux and average of 539 lux as shown in Figure 19 and Table 3.

According to the results of the measurements, the illumination levels on the first floor were effectively controlled to exhibit the art works in most of exhibition areas. The illumination levels on the third floor, however, 


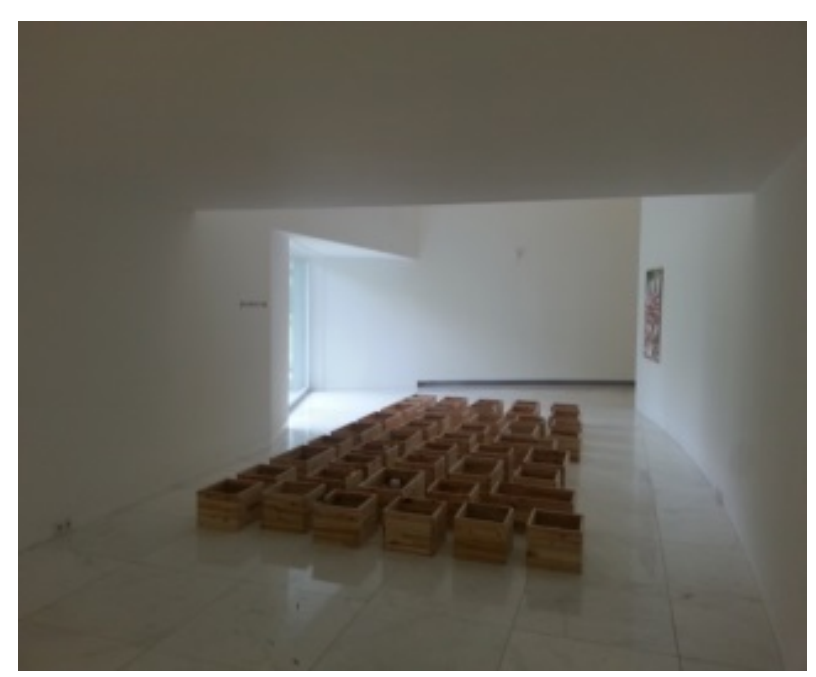

Figure 14. Sidelight of first floor.

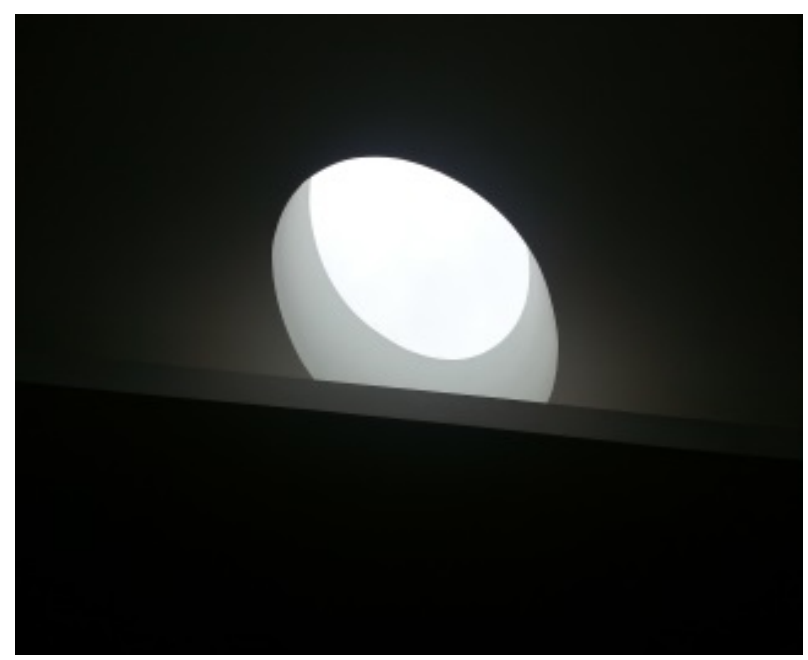

Figure 15. Skylight of second floor.

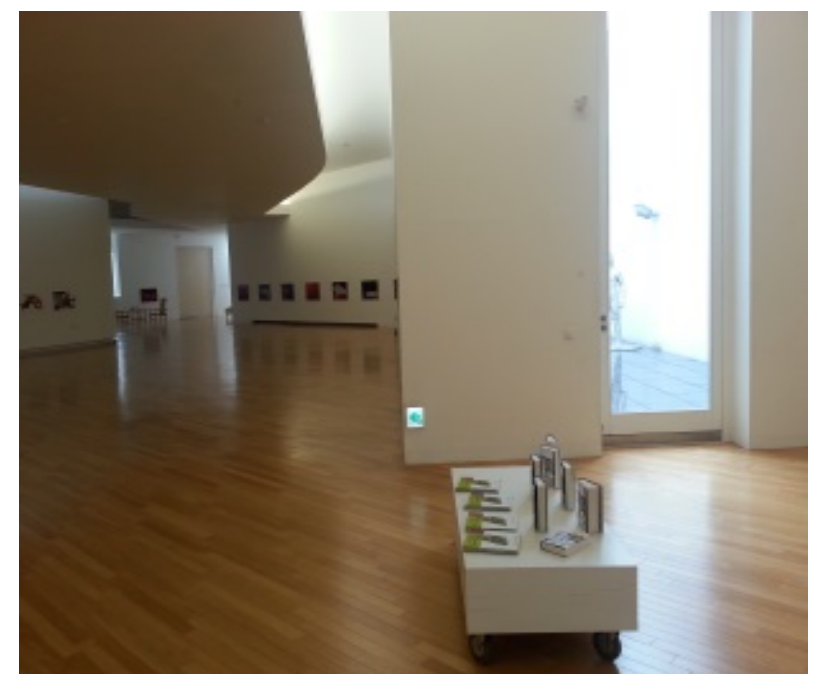

Figure 16. Sidelight of third floor. 


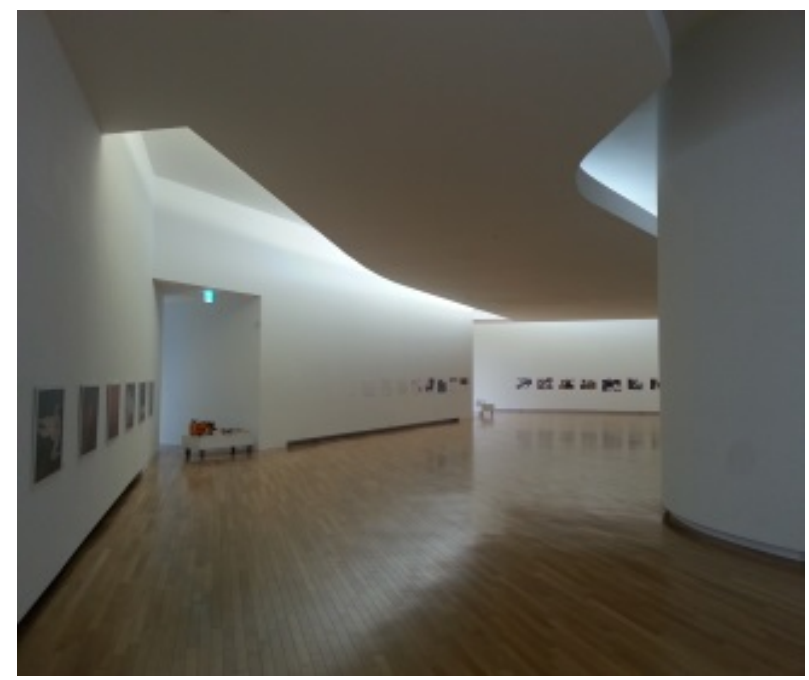

Figure 17. Toplight of third floor.

Table 1. Recommended illuminance levels (unit: Lux).

\begin{tabular}{|c|c|c|}
\hline \multicolumn{3}{|c|}{ Recommended total exposed limits in museum (IESNA) } \\
\hline Objects & Illuminance & Lux-hours per year \\
\hline Highly susceptible—silk, textiles, watercolors, furs, lace, etc. & 50 & 50,000 \\
\hline Moderately susceptible—oil painting, leather, wood, etc. & 200 & 480,000 \\
\hline Least susceptible—metal, glass, ceramic, stone, jewelry, etc. & \multicolumn{2}{|c|}{ Depends on exhibition situation } \\
\hline
\end{tabular}
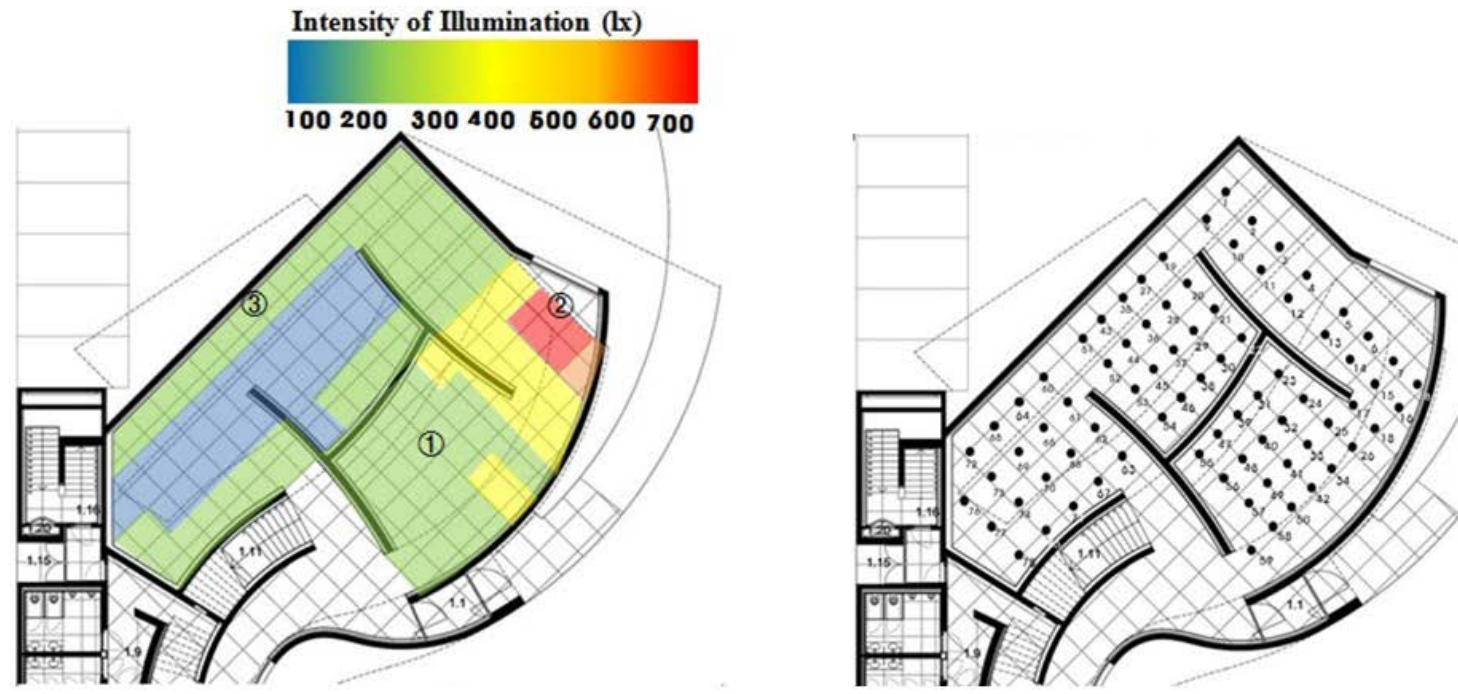

Figure 18. Measurements on the first floor.

were much higher than IESNA recommendations because of less controlled natural light entering through the skylights and windows. Therefore, more considerations to control the natural light are required for the stable lighting conditions.

\subsection{Survey of the Visitors' Satisfaction about the Lighting Conditions}

A survey was conducted to evaluate visitors' satisfaction under the lighting conditions of the Mimesis Art Museum 
Table 2. Measurements on the first floor according to the measurement points.

\begin{tabular}{|c|c|c|c|c|c|c|c|c|c|}
\hline MF01 & MF02 & MF03 & MF04 & MF05 & MF06 & MF07 & MF08 & MF09 & MF10 \\
\hline 224 & 197 & 203 & 305 & 427 & 757 & 681 & 522 & 230 & 190 \\
\hline MF11 & MF12 & MF13 & MF14 & MF15 & MF16 & MF17 & MF18 & MF19 & MF20 \\
\hline 280 & 290 & 380 & 410 & 440 & 390 & 350 & 370 & 180 & 152 \\
\hline MF21 & MF22 & MF23 & MF24 & MF25 & MF26 & MF27 & MF28 & MF29 & MF30 \\
\hline 141 & 192 & 320 & 295 & 275 & 260 & 187 & 160 & 141 & 202 \\
\hline MF31 & MF32 & MF33 & MF34 & MF35 & MF36 & MF37 & MF38 & MF39 & MF40 \\
\hline 240 & 273 & 280 & 302 & 190 & 159 & 142 & 201 & 238 & 270 \\
\hline MF41 & MF42 & MF43 & MF44 & MF45 & MF46 & MF47 & MF48 & MF49 & MF50 \\
\hline 273 & 275 & 186 & 168 & 138 & 184 & 238 & 265 & 265 & 270 \\
\hline MF51 & MF52 & MF53 & MF54 & MF55 & MF56 & MF57 & MF58 & MF59 & MF60 \\
\hline 190 & 155 & 120 & 154 & 265 & 260 & 260 & 260 & 240 & 181 \\
\hline MF61 & MF62 & MF63 & MF64 & MF65 & MF66 & MF67 & MF68 & MF69 & MF70 \\
\hline 146 & 130 & 175 & 174 & 145 & 137 & 200 & 170 & 146 & 137 \\
\hline MF71 & MF72 & MF73 & MF74 & MF75 & MF76 & MF77 & MF78 & & \\
\hline 200 & 150 & 147 & 150 & 190 & 160 & 172 & 170 & & \\
\hline
\end{tabular}

Maximum value: 757 lx, Minimum value: 130 lx, Average value: 239 lx Measurement interval: $1.6 \mathrm{~m}$. Measurement height: $1.0 \mathrm{~m}$
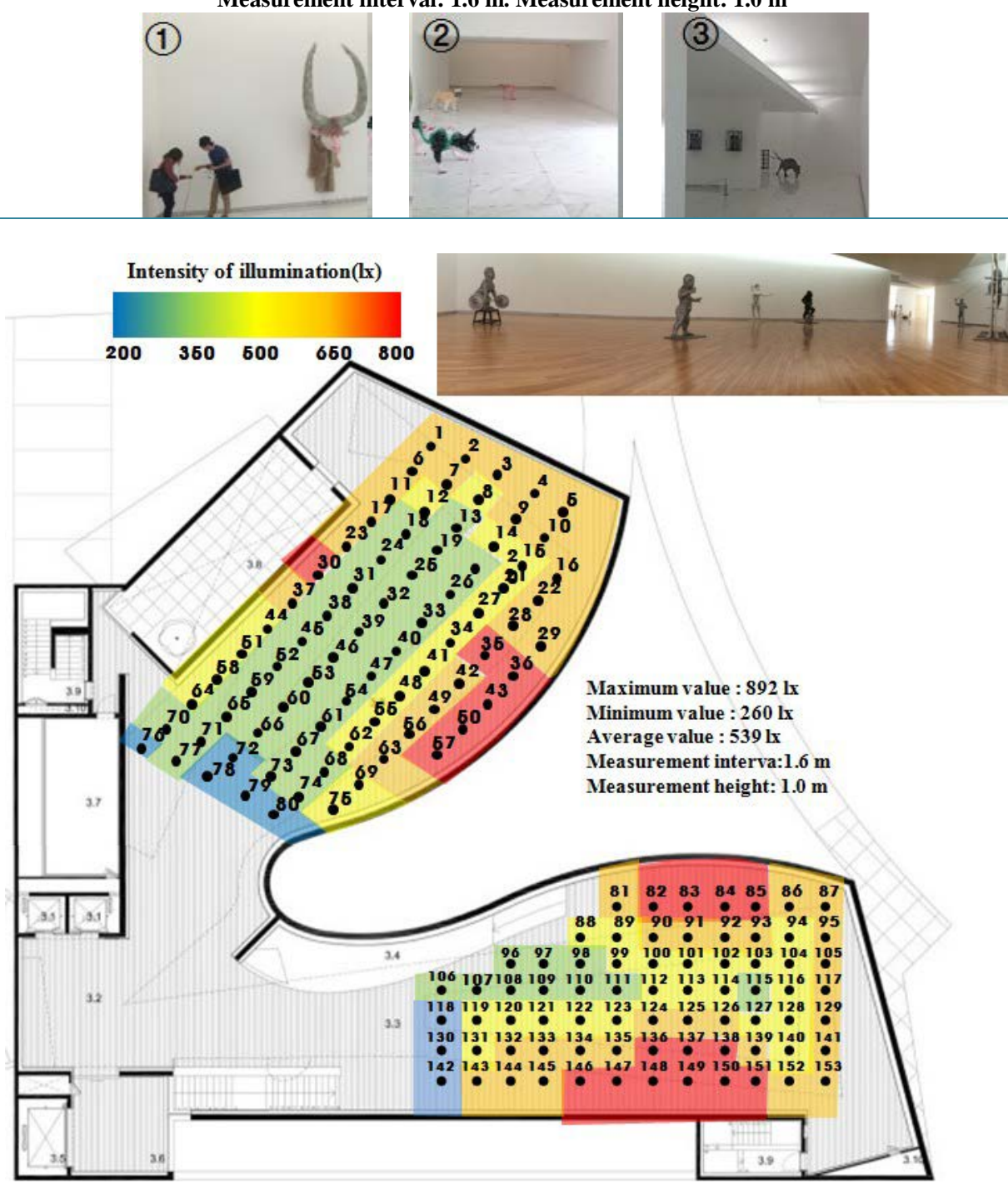

Figure 19. Measurements on the third floor. 
Table 3. Measurements on the third floor according to the measurement points.

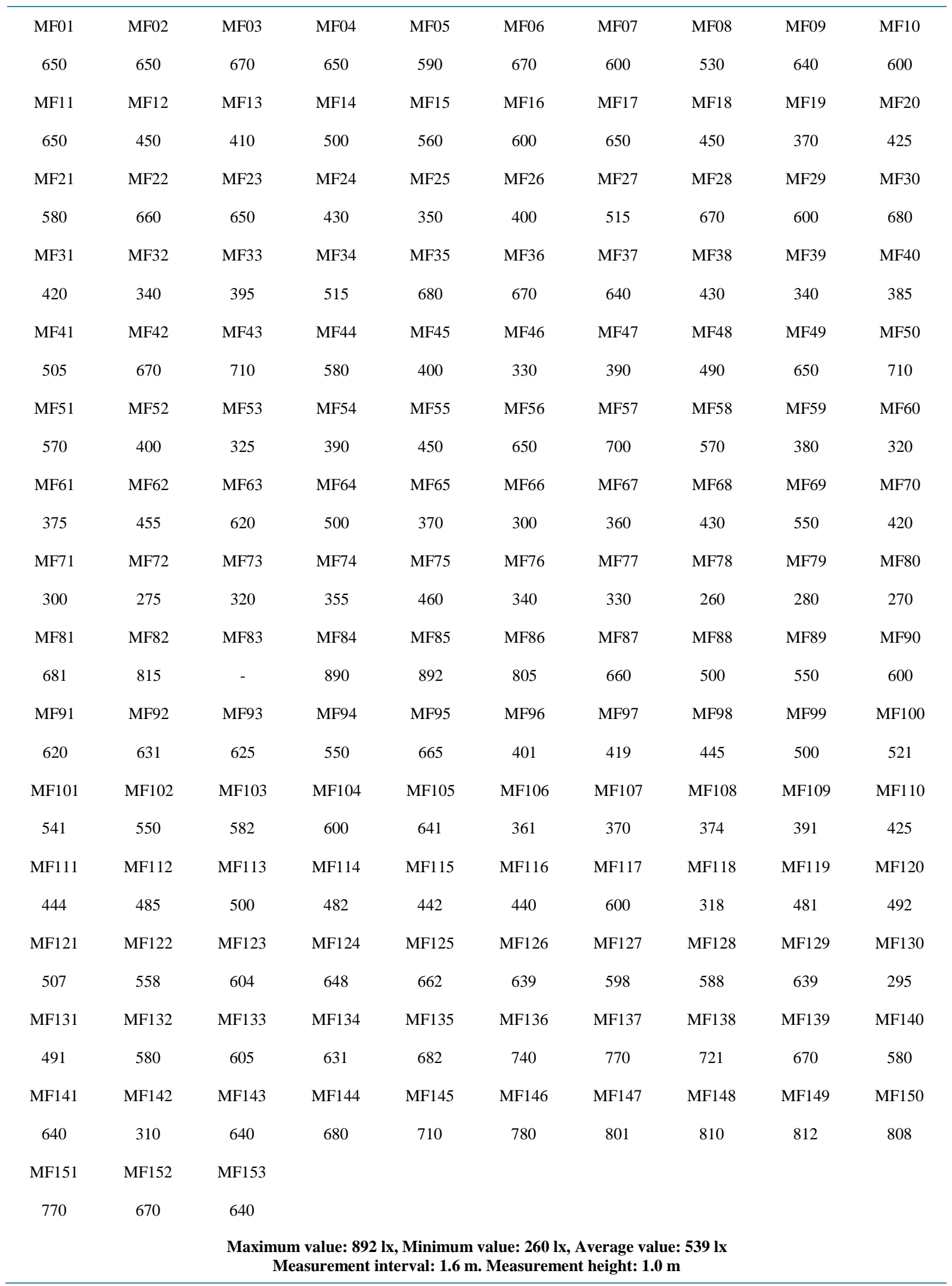


on the same days as the measurements were carried out. The answers of questionnaires were taken statistics by SPSS software, and then, the results were illustrated by bar charts that outlined the relevant figures. Each figure above the bars in the charts shows numbers of respondents to answer the questions. Questionnaires regarding the above issue distributed to 90 visitors, who were composed of 54 male and 36 female. The distribution of respondents is shown in Figure 20 and Figure 21.

The survey was comprised by 5 questionnaires as below:

- The architectural design factors to influence viewing satisfaction in the museum.

- The environmental considerations to offer stable exhibition spaces in the museums

- The visitors' satisfaction under the lighting condition of the museum

- The glare problem in exhibition areas of the museum

- The visitors' satisfaction under the natural lighting condition of the museum

1) What do you think is the most important design factor to influence viewing satisfaction in the museum?

The purpose of this question was to measure the visitors' opinions on architectural factors for museum design such as size of exhibition area, exhibition method, exhibition time, visitors' circulation, exhibition environment and rest area. Out of total 90 replies, 32 persons (36\%) responded that the visitors' circulation was the important factor, and 29 persons (32\%) answered that the exhibition method was the second most one (Figure 22).

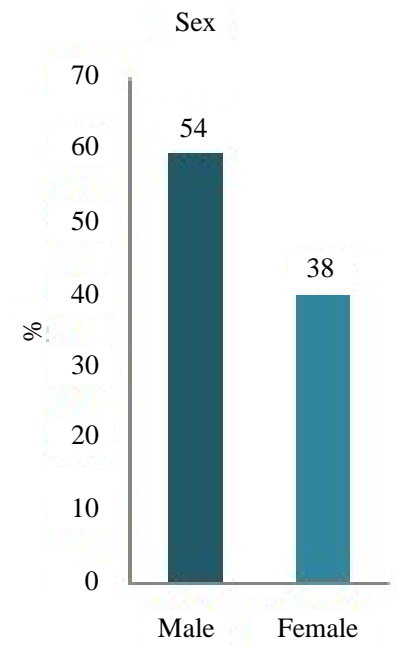

Figure 20. Respondent numbers according to sex.

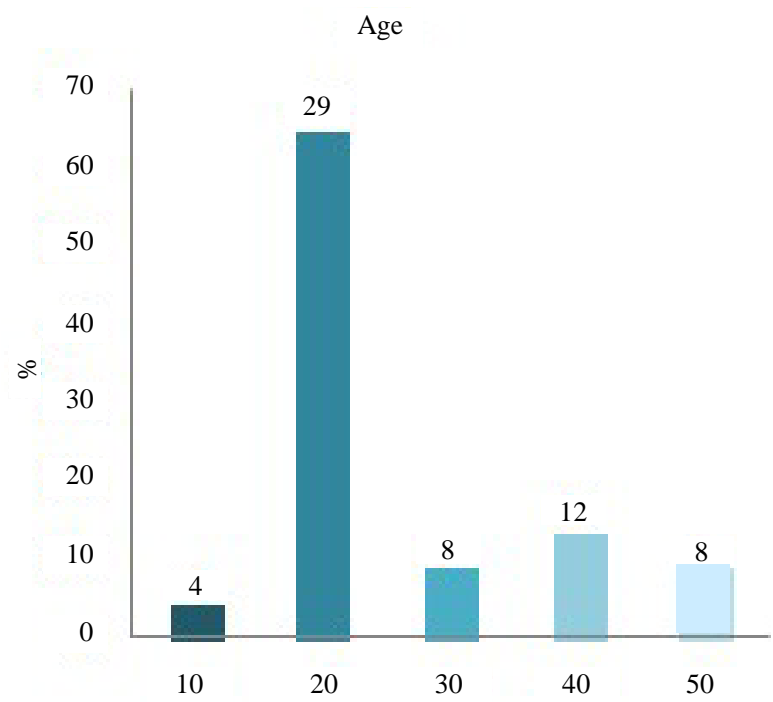

Figure 21. Respondent numbers according to age. 


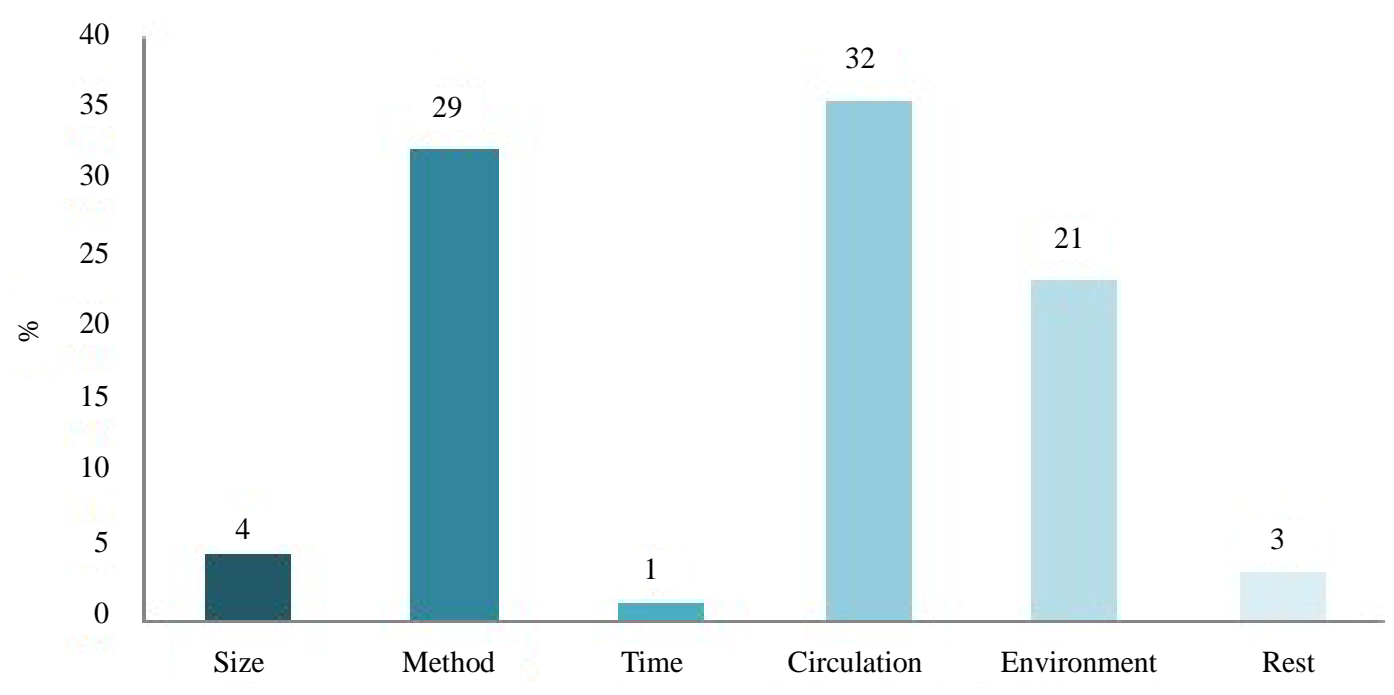

Figure 22. Design factors to influence viewing satisfaction.

2) What do you think is the most important factor to offer stable environment in exhibition spaces of the museum?

The aim of the question was to measure the visitors' opinions on environment factors for comfortable museum such as temperature, lighting, ventilation, noise, humidity and color. Out of total 90 replies, 41 persons (46\%) responded that the lighting was the important factor for the exhibition area, and 21 persons (23\%) answered that the color of the museum was the second most one (Figure 23).

3) How did you feel about the lighting condition of the museum when you have viewed exhibits?

The aim of the question was to measure the visitors' satisfaction on the lighting condition in the exhibition areas of the Museum, which was illuminated with the artificial light and natural light. Out of total 90 replies, 80 persons (89\%) responded that they were satisfied with the lighting condition of the museum. Only 2 persons (2\%) answered they had been unsatisfied with the lighting condition (Figure 24).

4) How much were you dazzled by glare problem in the exhibition areas of the museum while you were in the museum to view exhibits?

The purpose of the question was to measure the lighting quality of the museum by examining how much the visitors felt the glare in the Museum. Out of total 90 replies, 78 persons $(87 \%)$ responded that they were not dazzled the exhibition areas of the museum. Only 6 persons (7\%) answered the question they were dazzled by the glare problem (Figure 25).

5) How did you feel about illuminating the exhibition areas of the museum with the natural lighting? Was it helpful for you to view exhibits in the museum?

The purpose of the question was to measure the responses of the visitors about illuminating the exhibition areas of the museum with the natural light. Out of total 90 replies, 72 persons (87\%) responded that natural lighting was helpful to illuminate the exhibition areas of the museum. Only 6 persons (7\%) answered it was unhelpful to view exhibits in the museum (Figure 26).

As conducted from the results of the full survey, the closest attentions concerning the visitors' circulation, the display of exhibits and the lighting control need to be paid to offer comfortable environment for the museum. The answers of the respondents also showed that the natural light was so effective to illuminate the exhibition spaces of the museum.

\section{Conclusions}

The works of Alvaro Siza have been referred that they were not the theoretical architecture but the sensual and experiential one, and they were designed on the base of their locality. He was willing to use, in this connection, the natural light to be accord with climatic characteristics of regions. And, he drew the controlled natural light into indoor spaces, and made it harmonize with artificial light in order to create a living space and inspire a refreshing impression. 


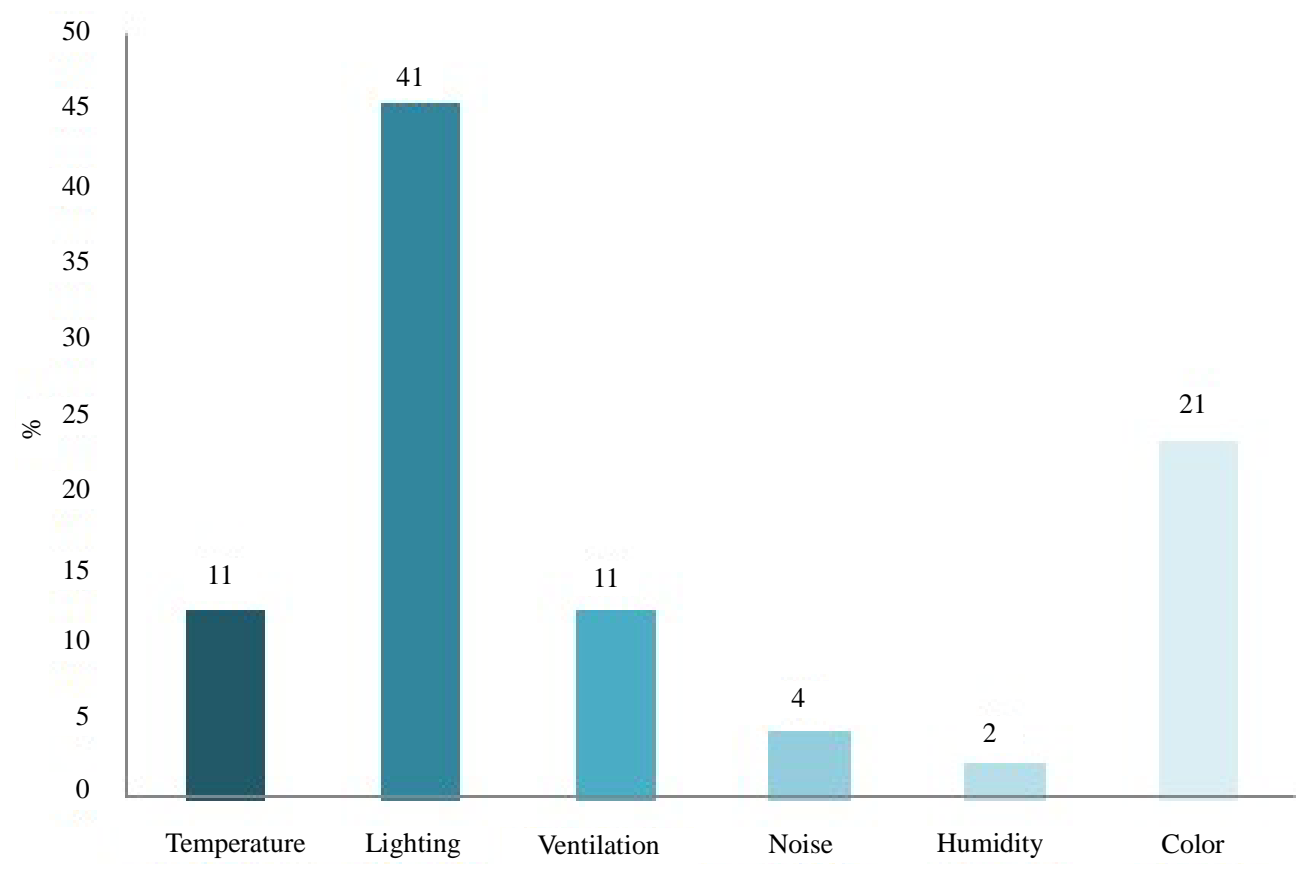

Figure 23. Environmental factors for comfortable museum.

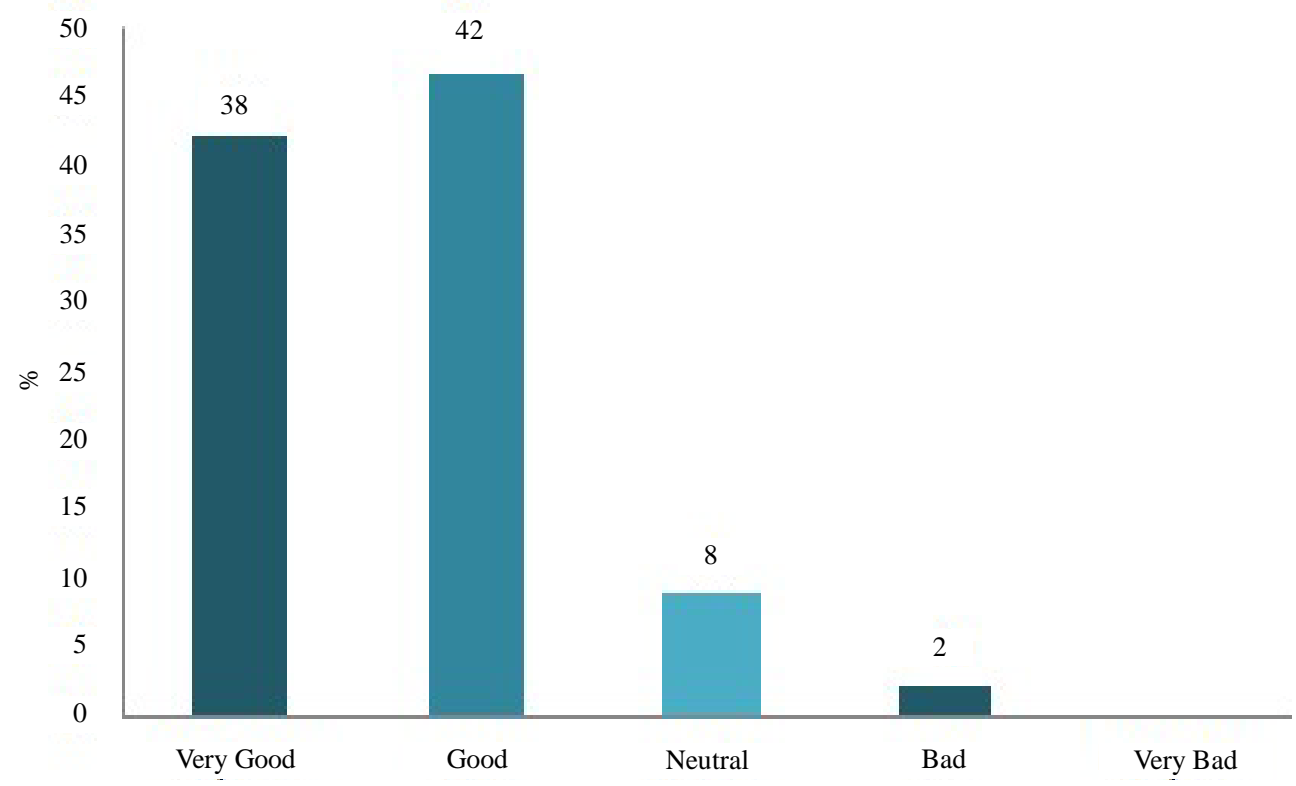

Figure 24. Visitors' satisfaction about lighting condition.

The Mimesis Art Museum has two void spaces on the inside and outside of the building, which formed a sharp contrast against the massive structure by the light. The light also endowed the museum with a sense of continuity that helped guide the visitors' movements. In addition, the refined light helped the visitors to experience the continuous forms and spaces, while using the changes of the light to stimulate the interest of visitors and highlight the sequence of spaces. Therefore, it successfully created architectural spaces and forms with a sense of continuity.

Meanwhile, the results of the measurements showed that the illumination levels of the Mimesis Art museum on the first floor were effectively controlled to display the art works. However, the illumination levels on the third floor were much higher than the IESNA recommendations for museum because of less controlled natural 


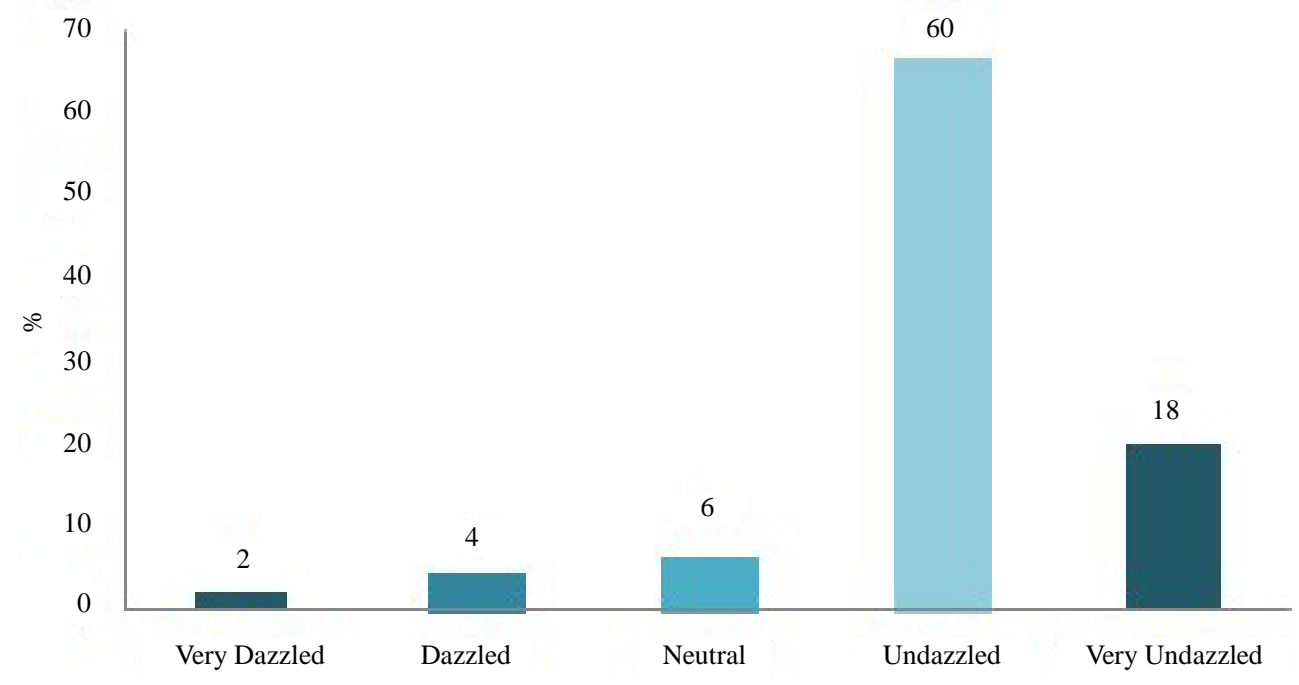

Figure 25. Glare problem.

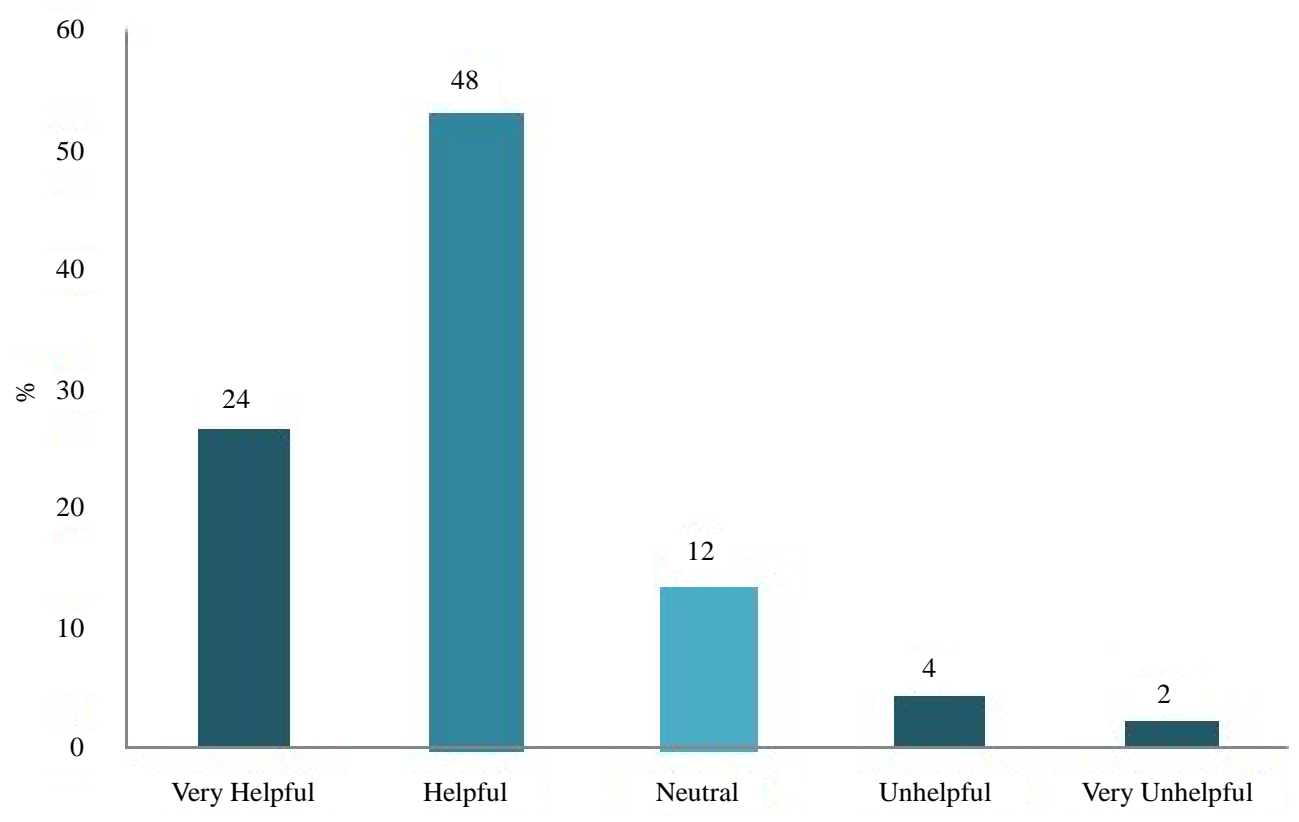

Figure 26. Responses about natural light.

light to enter through skylights and windows. Therefore, more considerations to control the natural light are needed to secure stable lighting environment.

As conducted from the results of the full survey, the closest attentions concerning the visitors' circulation, the display of exhibits and the lighting control need to be paid to offer comfortable environment for the museum. The answers of the respondents also showed that the natural light was so effective to illuminate the exhibition spaces of the museum.

On the base of this research, further study is going to be conducted to resolve the lighting problem of the Mimesis Art Museum in a practical and meaningful manner. And then, I will try to propose the daylighting design technology integrated into architectural design process.

\section{References}

[1] Kim, C.S. and Seo, K.W. (2014) The Architectural Expression of Space and Form Created by the Light in the Works of 
Alvaro Siza. Journal of Building Conctruction and Planning Research, 2, 118-131. http://dx.doi.org/10.4236/jbcpr.2014.22011

[2] Frampton, K. (1986) Prospects for a Critical Regionalism. The Yale Architectural Journal, the MIT Press, Perspecta, 20, 147-162.

[3] Chung, H.K. (2014) A Study on the Design Concept of Critical Regionalism through the Contemporary Archit Ecture. Journal of Korean Institute of Interior Design, 13, 20-28.

[4] Curtis, W.J.R. (1999) Notes on Invention: Alvaro Siza’, Alvaro Siza 1995-1999. El Croquis, Madrid.

[5] Lee, W.H. (2012) A Study on Alvaro Siza’s Strategy of Realizing Architectural Space Inducing Spatial ExperiencesFocusing on the Public Building Since 1985. Master Thesis, Seoul National University, South Korea.

[6] del Hoyo-Meléndez, J.M., Mecklenburg, M.F. and Doménech-Carbó, M.T. (2011) An Evaluation of Daylight Distribution as an Initial Preventive Conservation Measure at Two Smithsonian Institution Museums, Washington DC, USA. Journal of Cultural Heritage, 12, 54-64. http://dx.doi.org/10.1016/j.culher.2010.05.003

[7] Kim, C.S. and Seo, K.W. (2012) Integrated Daylighting Simulation into the Architectural Design Process for Museums. Building Simulation, 5, 325-336.

[8] IESNA (1998) Lighting Handbook, Reference and Application. 9th Edition, Illuminating Engineering, New York City. 
Scientific Research Publishing (SCIRP) is one of the largest Open Access journal publishers. It is currently publishing more than 200 open access, online, peer-reviewed journals covering a wide range of academic disciplines. SCIRP serves the worldwide academic communities and contributes to the progress and application of science with its publication.

Other selected journals from SCIRP are listed as below. Submit your manuscript to us via either submit@scirp.org or Online Submission Portal.
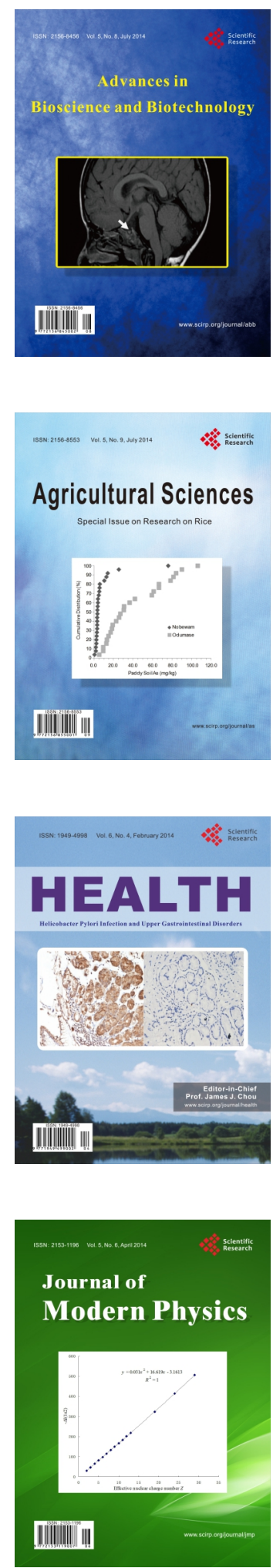
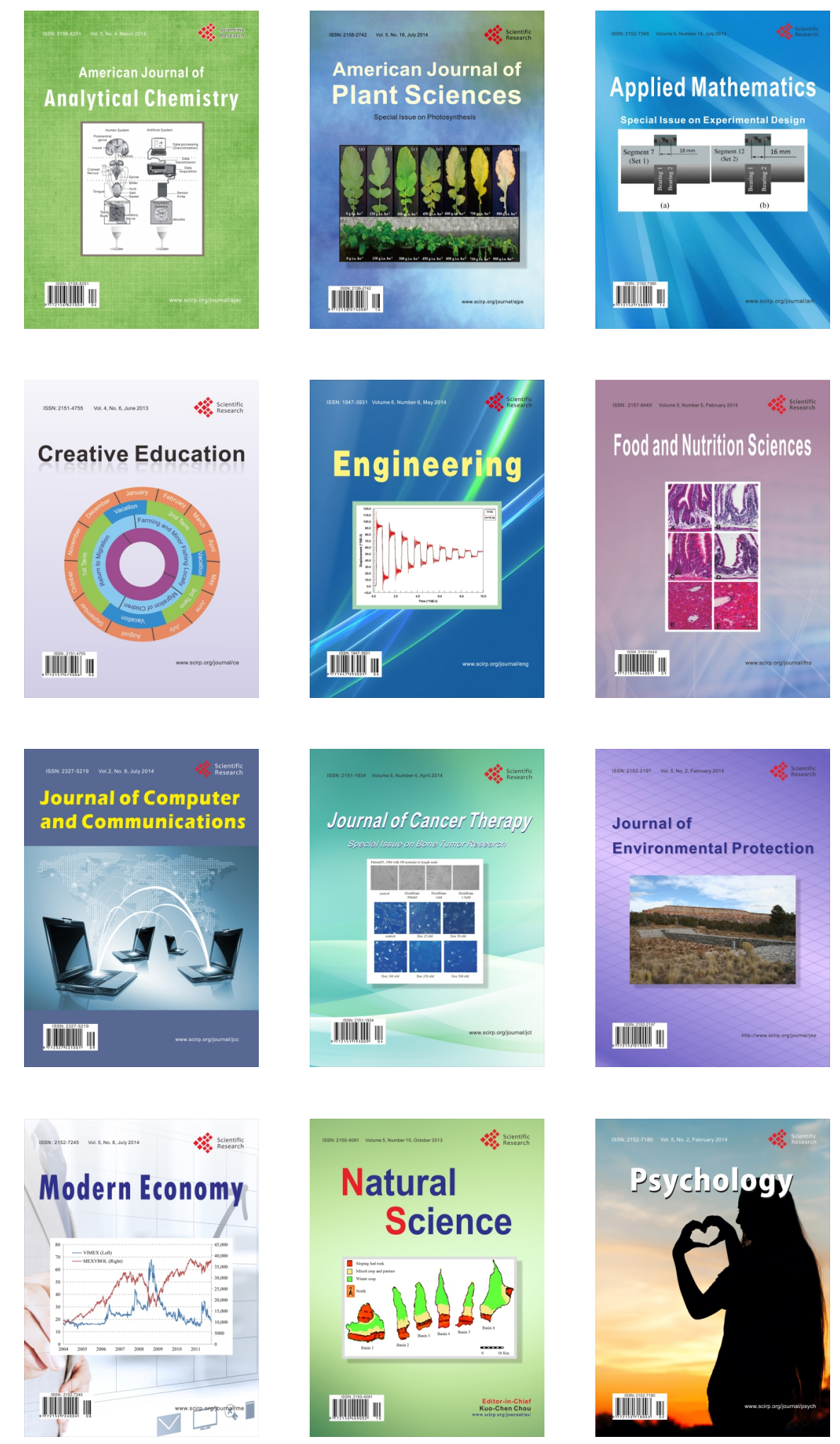